\title{
Snow metamorphism under alternating temperature gradients: Morphology and recrystallization in surface snow
}

\author{
B. R. Pinzer ${ }^{1}$ and M. Schneebeli ${ }^{1}$ \\ Received 16 June 2009; revised 21 September 2009; accepted 12 October 2009; published 4 December 2009.
}

[1] The composition of the lower atmospheric boundary layer can be strongly influenced by snow photochemistry. Surface snow, where air-snow interactions take place, is viewed as slowly changing quasi-isothermal snow, implied by the observation of mainly rounded snow crystals. The role of snow for photochemistry is therefore expected to be purely geometric. However, large temperature gradients are often observed in these layers, which would imply high recrystallization and faceting. In controlled laboratory experiments we showed that temperature gradients on the order of $100 \mathrm{~K} \mathrm{~m}^{-1}$ do not lead necessarily to faceting if their sign changes with a daily cycle. The shape of snow crystals does not reflect necessarily the metamorphic process. With time-lapse X-ray tomography, recrystallization rates as high as $60 \%$ of the total ice mass were observed during 12 hours. The high recrystallization rates in apparently isothermal snow not only contradict the current understanding of snow metamorphism, they also might influence chemical air-snow interactions. Citation: Pinzer, B. R., and M. Schneebeli (2009), Snow metamorphism under alternating temperature gradients: Morphology and recrystallization in surface snow, Geophys. Res. Lett., 36, L23503, doi:10.1029/2009GL039618.

\section{Introduction}

[2] The photochemistry of snow has received considerable attention since the discovery that polar boundary layer chemistry can be dominated by emissions of reaction products from snow [Grannas et al., 2007]. Modeling the interactions between snow cover and atmosphere from first principles is far from being realized. Physical properties of snow related to geometry such as specific surface area, density, light penetration depth, and diffusivity play an important role for chemical interactions [Domine et al., 2008]. However, since snow on the ground is not in thermodynamic equilibrium, it undergoes continuous structural changes, caused by water vapor diffusion through the pore space. Continued sublimation and condensation during metamorphism are likely to release or trap species. An increased uptake of $\mathrm{HNO}_{3}$ [Ullerstam and Abbatt, 2005] and mercury [Douglas et al., 2008] was demonstrated under nonequilibrium conditions. The partitioning of $\mathrm{HCl}$ between gas phase and ice has a maximum at a growth rate of about $5 \times 10^{16}$ molecules $\mathrm{cm}^{-2} \mathrm{~s}^{-1}$ [Dominé and Rauzy, 2004; Huthwelker et al., 2006]. Therefore, recrystallization in snow might have a significant impact on snow chemistry.

\footnotetext{
${ }^{1}$ WSL Institute for Snow and Avalanche Research SLF, Davos, Switzerland.
}

Copyright 2009 by the American Geophysical Union. 0094-8276/09/2009GL039618
[3] The current theory of dry snow metamorphism [Colbeck, 1983; Colbeck et al., 1990] recognizes two fundamental processes for recrystallization: equi-temperature (synonymous to isothermal) metamorphism (ETM), driven by differences in curvature, and temperature gradient metamorphism (TGM), driven by differences in temperature. While the former class is well described as a coarsening process similar to Ostwald ripening [Legagneux et al., 2004; Kaempfer and Schneebeli, 2007], there is currently only a qualitative understanding of the structural changes during TGM [Yosida, 1955; Marbouty, 1980]. In general, above a critical gradient on the order of $10-20 \mathrm{~K} \mathrm{~m}^{-1}$ faceted crystals were observed in the field [Colbeck, 1987], and similar results were obtained with growth experiments of single crystals in the laboratory [Colbeck, 1985].

[4] Near the snow surface, where chemical interactions with the atmospheric boundary layer take place, the sign of the temperature gradient in the snowpack often changes. Measurements in Greenland [Dadic et al., 2008] and in alpine snowpacks [Birkeland et al., 1998] have shown that daily cycles of radiative heating and cooling lead to an inversion of the temperature gradient in the topmost $20 \mathrm{~cm}$. In Antarctica, daily variations of temperature near the surface also exist but are less pronounced [Brandt and Warren, 1997]. Despite the ubiquity of alternating temperature gradients near the surface, their effects on mass transport and crystal morphology have neither been discussed nor experimentally investigated to date. In particular, the observation that rounded grain forms prevail in surface layers under temperature gradient conditions is inconsistent with the current understanding of snow metamorphism.

\section{Time-Lapse Study of Alternating Gradients}

\subsection{Experimental Protocol}

[5] During two weeks, sinusoidal temperatures with opposite amplitudes were imposed at the top and the bottom of a small snow column while it was simultaneously scanned in a cooled micro computer tomograph $(\mu \mathrm{CT} 80$, Scanco Medical) [Pinzer and Schneebeli, 2009]. The cylindrical sample chamber had a diameter of $53 \mathrm{~mm}$ and a height of $20 \mathrm{~mm}$.

[6] The snow was produced in a cold laboratory by condensing water vapor on nylon threads, similar to the process in clouds. The new snow consisting of dendritic crystals or fractured dendrites with a maximum extension of 1-2 mm was sieved into boxes $\left(144 \times 144 \times 66 \mathrm{~mm}^{3}\right)$ and stored for one week at $-4{ }^{\circ} \mathrm{C}$ to allow for equi-temperature metamorphism to increase the cohesion. We filled the sample holder by cutting out a $53 \mathrm{~mm}$ cylinder from the middle of the sintered snow block and pushing the core into the sample holder, with great care to avoid any mechanical disturbance of the core. $2-4 \mathrm{~mm}$ thick ice plates were 
frozen into the sample chamber (above and below the snow column) to provide a water vapor reservoir and guarantee good thermal contact. The density of the snow was determined by weighing the sample holder including the ice plates and again snow-filled. Binocular images were taken just before and after the experiments. After mounting the sample holder inside the $\mu \mathrm{CT}$, a radiograph was used to check the correct placing and physical contact of the core with the sample holder.

[7] The acceleration voltage in the X-ray tube was $45 \mathrm{keV}$, and the low-energy part of the spectrum $(<10 \mathrm{keV})$ was cut off by an aluminium filter. The sample was scanned with 1000 projections per $180^{\circ}$, with an integration time of $600 \mathrm{~ms}$ per projection. Only the innermost $36.9 \mathrm{~mm}$ of the total $53 \mathrm{~mm}$ diameter were scanned, at a resolution of $18 \mu \mathrm{m}$. The snow and aluminium outside the field of view were sufficiently homogeneous not to produce artifacts. The $\mu \mathrm{CT}$ was programmed to scan every $6 \mathrm{~h}$ a height of $7.488 \mathrm{~mm}$ in the center of the snow column. One scan took approximately $2 \mathrm{~h}$.

[8] The absolute $z$-position was not stable between subsequent scans due to the weight of the sample holder. To correct, a linear encoder for the $z$-position was built into the $\mu \mathrm{CT}$ for experiment $s 3$. Vapor mass fluxes could be evaluated only after this modification.

\subsection{Image Processing}

\subsubsection{Segmentation}

[9] Subvolumes of dimensions (300 voxel $)^{3}$ were cut out, filtered with a Gaussian filter $(\sigma=1.2$, support $=2)$, and segmented by matching the weighed density of the snow samples to the volumetric density of the binary images.

\subsubsection{Specific Surface Area}

[10] Specific surface area (SSA) [Kerbrat et al., 2008] is the ratio of ice surface area over ice volume (unit $\mathrm{m}^{-1}$ ). The surface area was extracted from the voxel data using a marching cubes algorithm [Lorensen and Cline, 1987]. This algorithm creates a triangulation of the surface by comparing cubes of eight voxels at the ice-air interface to the set of all possible configurations, one cube after another. The surface area is then given by the sum of the triangle areas.

\subsubsection{Ice and Pore Thickness Distribution}

[11] The ice and pore thickness distribution is calculated by a distance transform followed by fitting largest possible spheres inside the structure (pore space) yields the size distributions [Hildebrand and Ruegsegger, 1997].

\subsubsection{Mass Turnover Rate}

[12] Mass turnover rate is a measure of the amount of recrystallization in a macroscopic volume. During the period $\Delta t$ between two $\mu \mathrm{CT}$ scans, the mass $\Delta m$ changes phase from ice to vapor and is relocated by diffusion and deposition. $\Delta m$ is calculated by subtracting subsequent $\mu \mathrm{CT}$ images. Apart from the static voxels, the difference image contains the two components "sublimated" and "freshly deposited" voxels. We define the mass turnover rate $R$ within a representative macroscopic volume $V$ by

$$
R=\frac{1}{V} \frac{\Delta m}{\Delta t}
$$

\section{Results and Discussion}

[13] The experiment was repeated three times with different snow samples, each with a sinusoidal temperature gradient with an amplitude of $80-120 \mathrm{~K} \mathrm{~m}^{-1}$, representative for typical gradients found near the surface of natural snow [Birkeland et al., 1998]. Table 1 summarizes the snow characteristics and experimental conditions. The morphological evolution of all three samples was similar, as shown for sample $s 1$ in Figure 1. The most striking feature in Figure 1 is the lack of facets despite the high peak gradient of $\pm 89 \mathrm{~K} \mathrm{~m}^{-1}$. Due to the sinusoidal form of the temperature gradient the peak value was not acting all the time, but the previously observed threshold of $20 \mathrm{~K} \mathrm{~m}^{-1}$ for faceted growth was exceeded during $86 \%$ of the time. According to the International Classification of Seasonal Snow on the Ground (ICSSG) [Colbeck et al., 1990], the grain forms have to be classified as equilibrium form [Colbeck et al., 1990]. The current understanding underlying the ICSSG is that the morphology of snow grains uniquely reflects the metamorphic process that produced them. ETM produces rounded grains since the driving force is the minimization of free surface energy [Colbeck, 1980], while TGM produces faceted snow crystals due to high growth rates. The existence of a critical gradient for facet formation could not be explained yet. In addition, Colbeck [1985] found a faceted equilibrium form below $-10^{\circ} \mathrm{C}$. These complex morphological regimes are usually attributed to surface kinetic effects at the ice-air interface [Colbeck, 1987]. However, formation of facets was observed at low growth rates with a gradient of $3 \mathrm{~K} \mathrm{~m}^{-1}$ after 3 weeks [Flin and Brzoska, 2008], and even under isothermal conditions [Dominé et al., 2003]. These earlier findings and our results contradict the notion of a critical gradient. They suggest that the temporal stability of the gradient and thus the diffusion field plays an equally important role for facet formation. Consequently, many field observations that characterize the snow cover profile could misinterpret the process leading to the observed grain shapes.

[14] The geometrical evolution under alternating gradients suggests that the metamorphic processes of snow have to be extended with a third class, in addition to ETM and TGM. Due to the high mass transport, evolution of the structural parameters is more rapid than in the case of equi-temperature metamorphism [Schneebeli and Sokratov, 2004; Kaempfer and Schneebeli, 2007]. Real equi-temperature conditions take a single, isolated snow crystal several weeks until it is not recognizable as a precipitation particle any more [Bader et al., 1954]. In contrast, in a natural snowpack the precipitation particles often are decomposed within several days. Laboratory experiments [Kaempfer and Schneebeli, 2007] also show that the time scale for equi-temperature (or isothermal) metamorphism was longer in the laboratory than observed in the field. Our experiments lead to the conclusion that rounded, "equilibrium", grains observed in nature are in fact often due to alternating temperature gradients. However, snowpack models [Brun et al., 1992; Bartelt and Lehning, 2002] distinguish only between ETM and TGM, and different calibrated rate equations for the evolution of the geometrical parameters are applied in both regimes, but no rate equations exist for alternating temperature gradients.

[15] The continuous diffusion of water mass is mediated by the "hand-to-hand" mechanism, from one ice grain to the neighboring grain [Yosida, 1955]. The turnover rate $R$ gives the recrystallization within a macroscopic volume $V$ and is 
Table 1. Snow Characteristics and Experimental Conditions ${ }^{\mathrm{a}}$

\begin{tabular}{cccccccc}
\hline Name & $\rho\left(\mathrm{kg} \mathrm{m}^{-3}\right)$ & $\nabla T\left(\mathrm{~K} \mathrm{~m}^{-1}\right)$ & $\bar{T}\left({ }^{\circ} \mathrm{C}\right)$ & Duration $(\mathrm{d})$ & $\mathrm{SSA}_{\text {init }} / \mathrm{SSA}_{\text {final }}\left(\mathrm{mm}^{-1}\right)$ & $\mathrm{I} . \mathrm{Th}_{\text {init }}(\mu \mathrm{m})$ & $\mathrm{I} . \mathrm{Sp}_{\text {init }}(\mu \mathrm{m})$ \\
\hline$s 1$ & 127 & \pm 89.4 & -10.5 & 14.6 & $43.0 / 25.7$ & 68 & 301 \\
$s 2$ & 245 & \pm 87.0 & -2.3 & 14.6 & $23.2 / 19.7$ & 132 & 262 \\
$s 3$ & 180 & \pm 127.8 & -2.3 & 15.0 & $37.1 / 28.0$ & 82 \\
\hline
\end{tabular}

${ }^{a}$ Here $\rho$, snow density; $\nabla T$, amplitude of sine gradient; $\bar{T}$, mean temperature in snow sample; $\mathrm{SSA}_{\text {init }} / \mathrm{SSA}_{\text {final, }}$, initial and final specific surface area; $\mathrm{I}^{\mathrm{T}} \mathrm{h}_{\text {init }}$, initial mean ice thickness; and I.Sp $\mathrm{p}_{\text {init }}$, initial mean ice separation (pore thickness).

therefore influenced by the microstructure. More precisely, the more elementary "hand-to-hand" events are involved, i.e., the smaller the structure and pore sizes are, the higher the turnover rate is expected to be. Figure 2 shows this behavior. The mass turnover in our experiment $s 3$ (Figure $2 \mathrm{~b}$ ) was very high, between 2.0 and $3.5 \mathrm{~g} \mathrm{~m}^{-3} \mathrm{~s}^{-1}$, which was not expected given the equi-temperature like morphology. Taking an average value of $2.5 \mathrm{~g} \mathrm{~m}^{-3} \mathrm{~s}^{-1}$, this rate corresponds to a total daily turnover of $R_{\mathrm{TGM}}=216 \mathrm{~kg} \mathrm{~m}^{-3} \mathrm{~d}^{-1}$ - divided into one upward movement and one backward movement. Taking into account the density of experiment $s 3$ of $180 \mathrm{~kg}$ $\mathrm{m}^{-3}$, this means that during one half cycle of $12 \mathrm{~h}$ about $60 \%$ of the ice mass was relocated. A similar figure for ETM is difficult to measure directly, but an order of

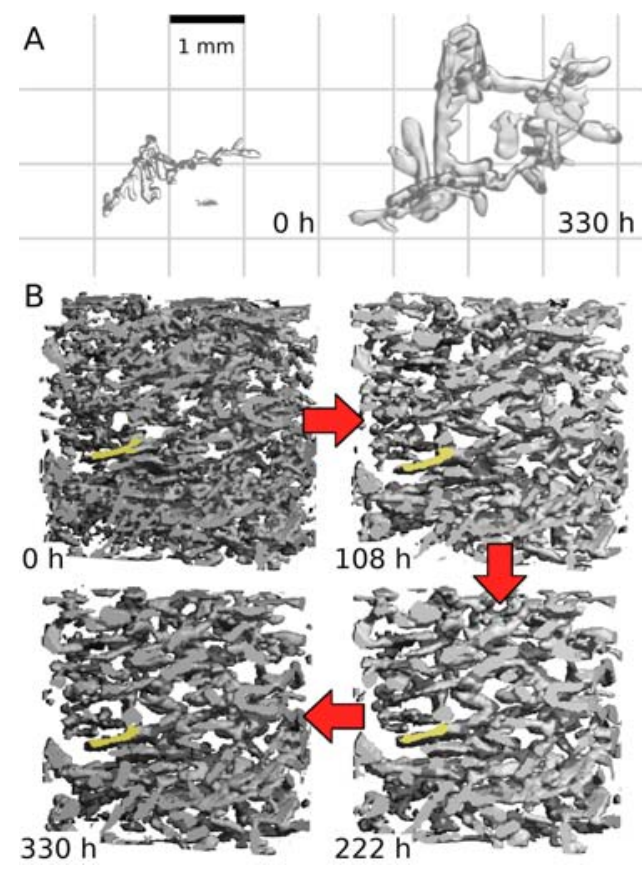

Figure 1. Morphological evolution for experiment $s 1$. (a) Microscopy images of snow grains. Initially, the grains typically showed characteristics of fresh snow like dendritic extensions. After the application of sinusoidal temperature gradients with amplitude $89.4 \mathrm{~K} \mathrm{~m}^{-1}$, the shape was much coarser but did not show any sign of conventional temperature gradient metamorphism. (b) Three-dimensional evolution of the snow. The size of the shown volumes is $3.6 \mathrm{~mm} \times 1.8 \mathrm{~mm} \times 3.6 \mathrm{~mm}$. One structural element has been marked yellow for orientation. The morphology of the structure evolves slowly, although more than four gradient cycles were between the images and considerable ice mass has been relocated. magnitude estimation for $R_{\mathrm{ETM}}$ can be obtained from recent observations of grain growth during ETM over one year [Kaempfer and Schneebeli, 2007]. Modeling the snow as a mono-disperse collection of spheres of the mean radius for each reported measurement and assuming that the density remains constant between two measurements, then an increase of radius from $r_{1}$ to $r_{2}$ implies a mass relocation per unit volume of

$$
\frac{\Delta m}{V}=\epsilon\left(1-r_{1}^{3} / r_{2}^{3}\right) \rho_{\text {ice }},
$$

where $\epsilon$ is the ice fraction and $\rho_{\text {ice }}$ the density of ice. Typical values at $-1.9^{\circ} \mathrm{C}$ and ice fraction $\epsilon=0.22$ [Kaempfer and Schneebeli, 2007] are $r_{1}=110 \mu \mathrm{m}$ and $r_{2}=125 \mu \mathrm{m}$ in $1000 \mathrm{~h}$, yielding $R_{\text {ETM }}=1.8 \times 10^{-5} \mathrm{~kg} \mathrm{~m}^{-3} \mathrm{~s}^{-1}$ or $1.5 \mathrm{~kg} \mathrm{~m}^{-3}$ per day. Different example values could lead to a variation of up to a factor of 5. However, compared to our results, this is more than two orders of magnitude lower. For chemical

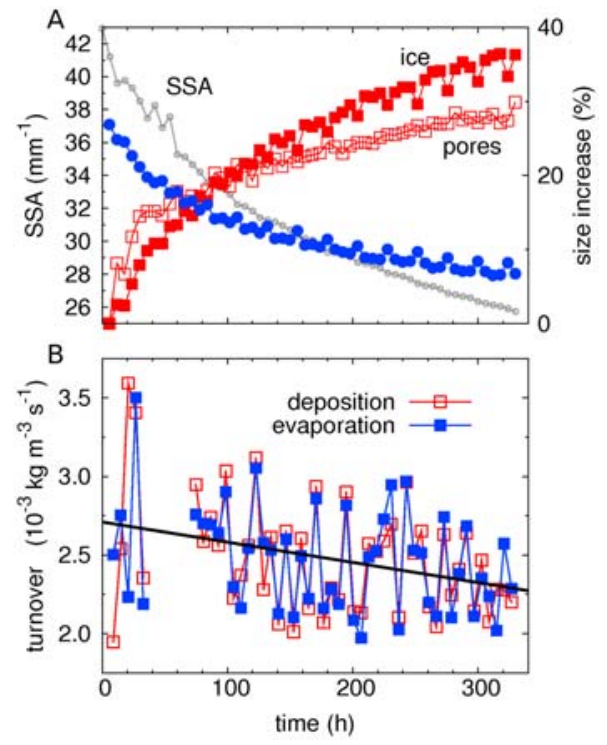

Figure 2. Temporal evolution of structural parameters and mass turnover of experiment $s 3$. (a) The microstructure evolves significantly, as seen by the $25 \%$ decrease of specific surface area (SSA) and the almost $40 \%$ increase of ice thickness and $30 \%$ increase of pore thickness. The SSA of experiment $s 1$ is shown in gray for comparison. (b) Mass turnover rate, averaged over the $6 \mathrm{~h}$ period between two $\mu \mathrm{CT}$ scans. The turnover rate is very high; it amounts to $60 \%$ of the total snow mass within one half cycle of the sine gradient $(12 \mathrm{~h})$. Note that in Figure $2 \mathrm{~b} 6$ data points are missing due to a failure of the $z$-position measurement. 
interactions with snow the high recrystallization rate under temperature gradients adds to the effect of the relatively large specific surface area accessible to gases.

\section{Conclusions}

[16] Our cycled temperature gradient measurements show that layers with rounded grains in natural snowpacks can be misinterpreted to be the result of equi-temperature metamorphism, although large alternating gradients have been acting. Although the constant mean temperature as well as the symmetric (diurnal) cycle in our experiments seem oversimplified compared to natural conditions, our results show that crystal growth rate is not the only decisive factor for faceting under a temperature gradient. The temporal stability of the diffusion field around a structural element must play an equally important role. We conclude that the metamorphic history of snow grains is not uniquely reflected in the morphology. We need a new model of snow metamorphism to account for these facts. The large volumetric turnover of up to $60 \%$ of the ice mass in one half-cycle in apparently isothermal snow must be considered for the interaction of chemicals with snow, since trace gases are likely to be buried and released with a $24 \mathrm{~h}$ cycle.

[17] Acknowledgments. This study was supported by the Swiss National Science Foundation, project 200021-108219.

\section{References}

Bader, H., R. Haefeli, E. Bucher, J. Neher, O. Eckel, and C. Thams (1954), Snow and its metamorphism, CRREL Rep. SIPRE TL 14, U.S. Army Cold Reg. Res. and Eng. Lab., Hanover, N. H.

Bartelt, P., and M. Lehning (2002), A physical SNOWPACK model for the Swiss avalanche warning: Part I: Numerical model, Cold Reg. Sci. Technol., $35,123-145$.

Birkeland, K. W., R. F. Johnson, and D. S. Schmidt (1998), Near-surface faceted crystals formed by diurnal recrystallization: A case study of weak layer formation in the mountain snowpack and its contribution to snow avalanches, Arct. Alp. Res., 30, 200-204.

Brandt, R. E., and S. G. Warren (1997), Temperature measurements and heat transfer in near-surface snow at the South Pole, J. Glaciol., 43, $339-351$

Brun, E., P. David, M. Sudul, and G. Brunot (1992), A numerical model to simulate snow-cover stratigraphy for operational avalanche forecasting, J. Glaciol., 38, 13-22.

Colbeck, S. C. (1980), Thermodynamics of snow metamorphism due to variations in curvature, J. Glaciol., 26, 291-301.

Colbeck, S. C. (1983), Theory of metamorphism of dry snow, J. Geophys. Res., 88, 5475-5482.

Colbeck, S. C. (1985), Temperature-dependence of the equilibrium form of ice, J. Cryst. Growth, 72, 726-732.

Colbeck, S. C. (1987), A review of the metamorphism and classification of seasonal snow cover crystals, in Avalanche Formation, Movement and Effects, edited by B. Salm and H. Gubler, IAHS Publ., 162, 3-34.
Colbeck, S., E. Akitaya, R. Armstrong, H. Gubler, J. Lafeuille, K. Lied, D. McClung, and E. Morris (1990), The international classification for seasonal snow on the ground, CRREL Rep. MP 2794, Int. Assoc. Sci. Hydrol., Gentbrugge, Belgium. (Available from USACRREL, CECRL-IB, 72 Lyme Rd., Hanover, NH 03755-1290.)

Dadic, R., M. Schneebeli, M. Lehning, M. A. Hutterli, and A. Ohmura (2008), Impact of the microstructure of snow on its temperature: A model validation with measurements from Summit, Greenland, J. Geophys. Res., 113, D14303, doi:10.1029/2007JD009562.

Dominé, F., and C. Rauzy (2004), Influence of the ice growth rate on the incorporation of gaseous $\mathrm{HCl}$, Atmos. Chem. Phys., 4, 2513-2519.

Dominé, F., T. Lauzier, A. Cabanes, L. Legagneux, W. F. Kuhs, K. Techmer, and T. Heinrichs (2003), Snow metamorphism as revealed by scanning electron microscopy, Microsc. Res. Tech., 62, 33-48.

Domine, F., M. Albert, T. Huthwelker, H. W. Jacobi, A. A. Kokhanovsky, M. Lehning, G. Picard, and W. R. Simpson (2008), Snow physics as relevant to snow photochemistry, Atmos. Chem. Phys., 8, 171-208.

Douglas, T. A., M. Sturm, W. R. Simpson, J. D. Blum, L. Alvarez-Aviles, G. J. Keeler, D. K. Perovich, A. Biswas, and K. Johnson (2008), Influence of snow and ice crystal formation and accumulation on mercury deposition to the Arctic, Environ. Sci. Technol., 42, 1542-1551.

Flin, F., and J. B. Brzoska (2008), The temperature-gradient metamorphism of snow: Vapour diffusion model and application to tomographic images, Ann. Glaciol., 49, 17-21.

Grannas, A. M., et al. (2007), An overview of snow photochemistry: Evidence, mechanisms and impacts, Atmos. Chem. Phys., 7, 4329-4373.

Hildebrand, T., and P. Ruegsegger (1997), A new method for the modelindependent assessment of thickness in three-dimensional images, J. Microsc., 185, 67-75, doi:10.1046/j.1365-2818.1997.1340694.x.

Huthwelker, T., M. Ammann, and T. Peter (2006), The uptake of acidic gases on ice, Chem. Rev., 106, 1375-1444, doi:10.1021/cr020506v.

Kaempfer, T. U., and M. Schneebeli (2007), Observation of isothermal metamorphism of new snow and interpretation as a sintering process, J. Geophys. Res., 112, D24101, doi:10.1029/2007JD009047.

Kerbrat, M., B. Pinzer, T. Huthwelker, H. W. Gaggeler, M. Ammann, and M. Schneebeli (2008), Measuring the specific surface area of snow with $\mathrm{X}$-ray tomography and gas adsorption: Comparison and implications for surface smoothness, Atmos. Chem. Phys., 8(5), 1261-1275.

Legagneux, L., A. S. Taillandier, and F. Dominé (2004), Grain growth theories and the isothermal evolution of the specific surface area of snow, J. Appl. Phys., 95, 6175-6184.

Lorensen, W. E., and H. E. Cline (1987), Marching cubes: A high resolution 3D surface construction algorithm, Comput. Graphics, 21, 163-169.

Marbouty, D. (1980), An experimental study of temperature-gradient metamorphism, J. Glaciol., 26, 303-312.

Pinzer, B., and M. Schneebeli (2009), Breeding snow: An instrumented sample holder for simultaneous tomographic and thermal studies, Meas. Sci. Technol., 20, 095705, doi:10.1088/0957-0233/20/9/095705.

Schneebeli, M., and S. A. Sokratov (2004), Tomography of temperature gradient metamorphism of snow and associated changes in heat conductivity, Hydrol. Processes, 18, 3655-3665.

Ullerstam, M., and J. P. D. Abbatt (2005), Burial of gas-phase $\mathrm{HNO}_{3}$ by growing ice surfaces under tropospheric conditions, Phys. Chem. Chem. Phys., 7, 3596-3600.

Yosida, Z. (1955), Physical studies on deposited snow. I. Thermal properties, Low Temp. Sci., 7, 19-74.

B. R. Pinzer and M. Schneebeli, WSL Institute for Snow and Avalanche Research SLF, CH-7260 Davos, Switzerland. (pinzer@slf.ch; schneebeli@ slf.ch) 